\title{
Clinical Utility of ${ }^{18}$ F-FDG PET/CT Concurrent with 131I Therapy in Intermediate-to-High-Risk Patients with Differentiated Thyroid Cancer: Dual-Center Experience with 286 Patients
}

\author{
Jeong Won Lee ${ }^{1}$, Sang Mi Lee², Dae Ho Lee ${ }^{3}$, and Yeo Joo Kim \\ ${ }^{1}$ Department of Nuclear Medicine, Yonsei University College of Medicine, Seoul, Korea; ${ }^{2}$ Department of Nuclear Medicine, \\ Soonchunhyang University Hospital, Cheonan, Korea; ${ }^{3}$ Department of Internal Medicine, Wonkwang University School of Medicine \\ and Hospital, Iksan, Korea; and ${ }^{4}$ Department of Internal Medicine, Soonchunhyang University Hospital, Cheonan, Korea
}

\begin{abstract}
Patients with differentiated thyroid carcinoma (DTC) are treated with ${ }^{131}$ I therapy after total thyroidectomy or surgical resection of recurrent tumor. However, some recurrent DTC lesions are not iodineavid, which affects further treatment planning. The aim of this study was to evaluate the clinical benefit of ${ }^{18} \mathrm{~F}-\mathrm{FDG}$ PET/CT performed concurrently with ${ }^{131}$ I therapy in DTC patients with intermediate to high risk. Methods: We retrospectively enrolled 286 DTC patients at 2 Korean medical centers who comprised 2 different patient groups: 28 patients who underwent adjuvant ${ }^{131}$ | treatment after curative surgical resection of recurrent tumor and 258 patients with intermediate to high risk who underwent ${ }^{131} \mathrm{I}$ ablation after total thyroidectomy. ${ }^{131} \mathrm{I}$ therapy and ${ }^{18} \mathrm{~F}-\mathrm{FDG} \mathrm{PET} / \mathrm{CT}$ scanning were performed on the same day. Administration of L-thyroxine was withheld from all enrollees for 4 wk before ${ }^{131}$ | treatment. Results: In 39 patients (14\%), ${ }^{18} \mathrm{~F}-\mathrm{FDG}$ PET/CT detected additional recurrent or metastatic lesions that were not detected on the posttherapy ${ }^{131}$ I scan, and the treatment plan was changed for 30 patients (10\%) based on such findings. Among the 28 patients receiving ${ }^{131} \mathrm{I}$ treatment after resection of recurrent tumor, PET/CT detected additional lesions in 46\%, and treatment was changed in $43 \%$. Assessing a subgroup of stage T3-T4N1 patients with tumor size $>2.0 \mathrm{~cm}$, among 258 patients undergoing ${ }^{131} \mathrm{I}$ ablation after total thyroidectomy, we found that $25 \%$ had additional positive PET/CT results, and treatment changed for $17 \%$. In contrast, $8 \%$ of stage T3-T4N1 patients with tumor size $\leq 2.0 \mathrm{~cm}, 6 \%$ of stage T1-T2N1 patients, and 3\% of stage T3-T4N0 patients had additional positive PET/CT findings. Conclusion: ${ }^{18} \mathrm{~F}-\mathrm{FDG} \mathrm{PET} / \mathrm{CT}$ performed concurrently with ${ }^{131}$ I therapy detected additional lesions in $14 \%$ of DTC patients and was particularly helpful for detecting additional lesions in patients undergoing ${ }^{131} \mid$ therapy after resection of recurrent tumor or in stage T3-T4N1 patients with tumor size $>2.0 \mathrm{~cm}$.
\end{abstract}

Key Words: differentiated thyroid cancer; ${ }^{18} \mathrm{~F}$-fluorodeoxyglucose; positron emission tomography; radioiodine therapy

J Nucl Med 2013; 54:1230-1236

DOI: $10.2967 /$ jnumed.112.117119

Received Nov. 11, 2012; revision accepted Mar. 28, 2013.

For correspondence or reprints contact: Sang Mi Lee, Soonchunhyang University Hospital, 23-20, Byeongmyeong-dong, Dongnam-gu, Cheonan, Chungcheongnam-do, Korea, 330-721.

E-mail: gareen@naver.com

Published online Jun. 27, 2013.

COPYRIGHT (C) 2013 by the Society of Nuclear Medicine and Molecular Imaging, Inc.
$\mathbf{T}$ he standard treatment protocol for differentiated thyroid carcinoma (DTC) is complete surgical resection of tumor lesions, followed by ${ }^{131}$ I therapy (1). ${ }^{131} \mathrm{I}$ treatment has been shown to be beneficial in reducing cancer recurrence and cancer-specific mortality $(2,3)$. However, in certain patients with DTC, the tumor cells lose their ability to trap iodine, including ${ }^{131} \mathrm{I}$. These iodinenegative tumor cells are not curable with ${ }^{131}$ I treatment. They are more aggressive and are associated with a poorer prognosis than tumors that can uptake iodine (4-6). The early detection of iodinenegative DTC lesions is important, because it triggers an adjustment in the treatment strategy: surgical resection, external-beam radiation therapy (EBRT), or multikinase inhibitor therapy will be selected rather than ${ }^{131} \mathrm{I}$ treatment.

${ }^{18} \mathrm{~F}-\mathrm{FDG}$ PET/CT is useful for the detection of recurrent DTC lesions, especially in patients with iodine-negative tumors and elevated serum thyroglobulin levels (6-10). Furthermore, recent studies showed that ${ }^{18} \mathrm{~F}$-FDG PET can detect DTC lesions more accurately under thyroid-stimulating hormone (TSH) stimulation than under TSH suppression (11-13). Because ${ }^{131} \mathrm{I}$ treatment is performed in the context of an elevated serum TSH level, concurrent ${ }^{18} \mathrm{~F}$-FDG PET with ${ }^{131} \mathrm{I}$ treatment could be beneficial for detecting recurrent DTC lesions, especially iodine-negative lesions, and for planning further treatment. However, there has been only one study to evaluate the role of ${ }^{18}$ F-FDG PET performed concurrently with ${ }^{131}$ I treatment under TSH stimulation (14).

In this study, we evaluated the usefulness of ${ }^{18} \mathrm{~F}-\mathrm{FDG}$ PET/CT performed concurrently with ${ }^{131}$ I therapy for detecting DTC lesions in patients with intermediate to high risk at 2 Korean medical centers. Moreover, we evaluated the relationship between tumor factors and positive PET/CT findings to find which patient group would benefit most from this strategy.

\section{MATERIALS AND METHODS}

\section{Patients}

We reviewed the electronic medical records of all DTC patients who underwent ${ }^{131}$ I treatment at 2 Korean medical centers (Cheonan Soonchunhyang University Hospital [CSUH] and Jeju National University Hospital [JNUH]). Of these patients, we retrospectively enrolled 286 patients who underwent ${ }^{18} \mathrm{~F}$-FDG PET/CT concurrently with ${ }^{131}$ I treatment. The enrolled patients comprised 2 different patient groups: those who underwent ${ }^{131}$ I ablation after total thyroidectomy and those who underwent adjuvant ${ }^{131}$ I treatment after intended curative 
TABLE 1

Characteristics of Study Subjects $(n=286)$

\begin{tabular}{|c|c|c|}
\hline Characteristic & $n$ or mean $\pm S D$ & $\%$ or range \\
\hline Age (y) & $51 \pm 13$ & $18-87$ \\
\hline \multicolumn{3}{|l|}{ Sex } \\
\hline Male & 57 & 20 \\
\hline Female & 229 & 80 \\
\hline \multicolumn{3}{|l|}{ Histopathology } \\
\hline Papillary & 280 & 98 \\
\hline Follicular & 6 & 2 \\
\hline \multicolumn{3}{|l|}{ Stage* $^{\star}$} \\
\hline $\mathrm{T} 1-\mathrm{T} 2 \mathrm{NO}$ & 2 & 1 \\
\hline $\mathrm{T} 1-\mathrm{T} 2 \mathrm{~N} 1$ & 66 & 23 \\
\hline T3-T4NO & 44 & 15 \\
\hline T3-T4N1 & 174 & 61 \\
\hline \multicolumn{3}{|l|}{ Dose of ${ }^{131}$ I } \\
\hline 3.7 GBq (100 mCi) & 41 & 14 \\
\hline $5.6 \mathrm{GBq}(150 \mathrm{mCi})$ & 235 & 82 \\
\hline $7.4 \mathrm{GBq}(200 \mathrm{mCi})$ & 10 & 4 \\
\hline Size of primary tumor $(\mathrm{cm})^{\dagger}$ & $1.5 \pm 1.1$ & $0.3-6.8$ \\
\hline Serum TSH level (IU/mL) & $88.1 \pm 22.1$ & $30.7-100.0$ \\
\hline Serum thyroglobulin level $(\mathrm{ng} / \mathrm{mL})^{\ddagger}$ & $25.8 \pm 91.8$ & $0.1-1000.0$ \\
\hline \multicolumn{3}{|c|}{$\begin{array}{l}{ }^{*} \text { In patients with adjuvant }{ }^{131} \text { I treatment after surgical resection of recurrent lesion, initial histopathologic stage was used. } \\
{ }^{\dagger} \text { Measured only in patients with }{ }^{131} \text { I ablation after total thyroidectomy. } \\
\left.{ }^{\ddagger} \text { Calculated for patients with negative antithyroglobulin antibody ( } 214 \text { patients, } 75 \%\right) \text {. }\end{array}$} \\
\hline
\end{tabular}

surgical resection of recurrent neck lesions. Among the former group, only those with intermediate to high risk were enrolled, according to the guidelines of the American Thyroid Association (1). Patients with a history of malignant tumor other than DTC were excluded from the study. No patient had gross residual tumor lesions after an operation. The interval between an operation and ${ }^{131} \mathrm{I}$ treatment ranged from 1 to 6 mo (median, $3 \mathrm{mo}$ ). The therapeutic ${ }^{131} \mathrm{I}$ dose ranged from $3.7 \mathrm{GBq}$ $(100 \mathrm{mCi})$ to $7.4 \mathrm{GBq}(200 \mathrm{mCi})$. In all patients, replacement of L-thyroxine $\left(\mathrm{T}_{4}\right)$ was discontinued for $4 \mathrm{wk}$ before ${ }^{131} \mathrm{I}$ treatment, and patients received replacement L-triiodothyronine $\left(T_{3}\right)$ for the first 2 wk of this period. Additionally, all patients were on a low-iodine diet for at least $2 \mathrm{wk}$ before the ${ }^{131}$ I therapy. Recombinant human TSH was not used in all patients. ${ }^{18} \mathrm{~F}$-FDG PET/CT scanning was performed just before the ${ }^{131}$ I treatment, on the same day. At both medical centers, serum TSH, thyroglobulin, and antithyroglobulin antibody levels were measured in the collected blood samples on the day of ${ }^{131}$ I treatment using an electrochemiluminescence immunoassay. At the time of ${ }^{131} \mathrm{I}$ treatment, all patients had serum TSH levels $>30 \mathrm{IU} / \mathrm{mL}$. Wholebody ${ }^{131} \mathrm{I}$ scans were obtained at $3-5 \mathrm{~d}$ and at $7-9 \mathrm{~d}$ after ${ }^{131} \mathrm{I}$ treatment. All patients signed a written informed consent form for the ${ }^{18} \mathrm{~F}-\mathrm{FDG}$ PET/CT and ${ }^{131}$ I treatment, and this study was approved by the Institutional Review Board of both medical centers.

\section{F-FDG PET/CT Scans}

The ${ }^{18} \mathrm{~F}-\mathrm{FDG}$ PET/CT scans were obtained using a Gemini PET/CT scanner (Philips) at CSUH and a Biograph 40 scanner (Siemens Medical Solutions) at JNUH. All patients were instructed to fast at least $6 \mathrm{~h}$ before the ${ }^{18} \mathrm{~F}-\mathrm{FDG}$ administration. Patients were intravenously injected with ${ }^{18} \mathrm{~F}$-FDG $(5.18 \mathrm{MBq} / \mathrm{kg}$ for the Gemini scanner or 6.29 $\mathrm{MBq} / \mathrm{kg}$ for the Biograph 40 scanner) $1 \mathrm{~h}$ before a PET/CT scan. First, $\mathrm{CT}$ images were acquired for attenuation correction without contrast enhancement. Then, PET images were acquired from the skull base to the proximal femur at $2.5 \mathrm{~min}$ per bed position for the Gemini scanner and at 2 min per bed position for the Biograph 40 scanner. PET images were reconstructed into a $128 \times 128$ matrix using an iterative algorithm with an attenuation correction.

\section{Posttherapy ${ }^{131}$ I Scans}

Posttherapy ${ }^{131}$ I whole-body scans were obtained using a large field-of-view dual-head $\gamma$-camera (Xeleris [GE Healthcare] at CSUH and Vertex V60 [ADAC] at JNUH) equipped with a medium-energy parallel-hole collimator. The continuous acquisition mode was used, with a scanning speed of $12 \mathrm{~cm} / \mathrm{min}$ for the Xeleris camera and $13 \mathrm{~cm} /$ min for the Vertex V60 camera. Anterior and posterior whole-body images were acquired, and additional spot images were acquired where abnormal ${ }^{131}$ I uptake was shown on the whole-body images.

\section{Image Analysis}

All ${ }^{18} \mathrm{~F}$-FDG PET/CT and posttherapy ${ }^{131} \mathrm{I}$ whole-body images were visually assessed by 2 experienced nuclear medicine physicians. On posttherapy ${ }^{131}$ I scans, lesions showing abnormally increased ${ }^{131} \mathrm{I}$ uptake other than remnant thyroid uptake or physiologic uptake were considered positive lesions. All lesions on PET/CT images were classified using a 4-point scale: 1 , definitely benign, physiologic ${ }^{18} \mathrm{~F}-\mathrm{FDG}$ uptake or lesions without abnormal ${ }^{18} \mathrm{~F}-\mathrm{FDG}$ uptake; 2 , probably benign, lesions with mild-to-moderate ${ }^{18} \mathrm{~F}$-FDG uptake showing benign features on the CT images; 3, probably metastatic, lesions with mildto-moderate ${ }^{18} \mathrm{~F}-\mathrm{FDG}$ uptake showing indeterminate or malignant features on CT images or lesions with relatively high ${ }^{18} \mathrm{~F}-\mathrm{FDG}$ uptake in comparison with size; and 4, definitely malignant, lesions with intense ${ }^{18}$ F-FDG uptake. The lesions with a score of 3 or 4 are classified as positive PET/CT lesions. The locations of positive lesions on both images were classified as thyroid bed, right neck, left neck, mediastinum, and other distant organs. All patients with positive findings on ${ }^{18} \mathrm{~F}-\mathrm{FDG}$ PET/CT or ${ }^{131} \mathrm{I}$ scans underwent further diagnostic work-up, and findings were determined to be true-positive when the lesions were histopathologically confirmed as recurrent or metastatic lesions of DTC or verified on subsequent follow-up imaging studies including ultrasonography, CT, PET/CT, or ${ }^{131}$ I scanning. If the true-positive lesions were only positive on ${ }^{18} \mathrm{~F}-\mathrm{FDG}$ PET/CT and negative on ${ }^{131} \mathrm{I}$ scans, patients were considered to have additional positive lesions on PET/CT. Furthermore, if the classified locations of true-positive lesions on PET/CT scans were incongruent with the positive lesions on 


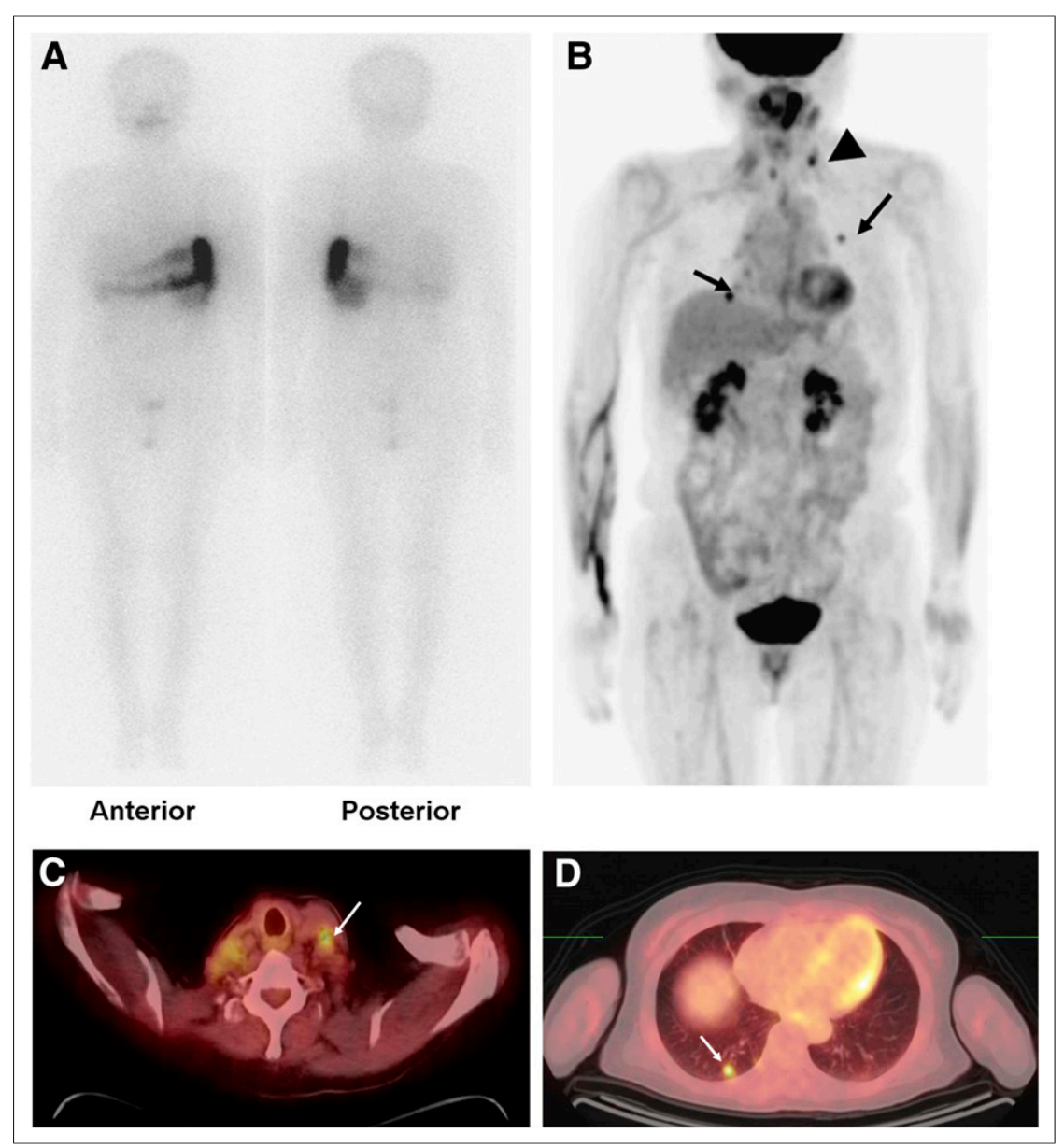

FIGURE 1. A 72-y-old woman with papillary thyroid cancer underwent ${ }^{131}$ I ablation (3.7 GBq) 4 mo after total thyroidectomy (histopathologic stage, T3N1). Posttherapy ${ }^{131}$ I scan (A) showed no abnormal ${ }^{131}$ I uptake, suggesting remnant thyroid uptake or metastatic lesion. However, maximal-intensity-projection image $(B)$ and transaxial images $(C$ and $D)$ of ${ }^{18} \mathrm{~F}$ FDG PET/CT showed areas of increased focal uptake in left neck region (arrowhead) and in lung (arrow), suggesting multiple metastatic lesions. Neck lesion was histopathologically diagnosed as metastatic lesion.

${ }^{131}$ I scans, the patients were considered to have additional positive lesions on PET/CT. If the classified locations of true-positive lesions on PET/CT and ${ }^{131}$ I scans were the same, the lesions were considered positive on both PET/CT and ${ }^{131} \mathrm{I}$ scans, and the patients had no additional PET/CT lesions.

All enrolled patients were classified as having additional positive lesions on ${ }^{18} \mathrm{~F}$-FDG PET/CT, the same positive lesions on PET/CT and ${ }^{131} \mathrm{I}$ scans, positive lesions on ${ }^{131} \mathrm{I}$ scans with negative PET/CT findings, and negative findings on both PET/CT and ${ }^{131}$ I scans. We calculated the ratios of patients with additional positive lesions on PET/CT and the ratio of patients with treatment change due to PET/CT findings. The treatment change was defined as abandonment of further ${ }^{131} \mathrm{I}$ treatment or thyroid hormone suppression therapy in favor of surgical resection, EBRT, or multikinase inhibitor therapy. Afterward, tumor stage and size, patients' age, and serum thyroglobulin level were evaluated as predictive factors for positive findings on PET/CT. The frequency of additional PET/CT lesions was compared among patients grouped according to the tumor stage and size and patients' age using the $\chi^{2}$ and Fisher exact tests. Furthermore, the Mann-Whitney test was performed to compare the serum thyroglobulin level between patients with positive and negative PET/ CT findings. All statistical analyses were performed with SPSS software (SPSS), and $P$ values less than 0.05 were considered statistically significant.

\section{RESULTS}

\section{Patient Characteristics}

Characteristics of the enrolled 286 patients are summarized in Table 1 . Of these patients, $258(90 \%)$ underwent ${ }^{131} \mathrm{I}$ ablation after total thyroidectomy. The remaining 28 patients $(10 \%)$ underwent adjuvant ${ }^{131}$ I treatment after intended curative surgical resection of recurrent lesions. Distant metastatic lesions were found in 13 patients $(5 \%)$ on ${ }^{18} \mathrm{~F}$-FDG PET/CT or posttherapy ${ }^{131} \mathrm{I}$ scans.

${ }^{18} \mathrm{~F}-\mathrm{FDG}$ PET/CT showed positive lesions in 50 patients (17\%) among the enrolled 286. This group of 50 patients includes 39 (14\%) with additional positive lesions on the ${ }^{18} \mathrm{~F}$ FDG PET/CT scan that were not observed on the posttherapy ${ }^{131} \mathrm{I}$ scan (Fig. 1): in the neck lymph nodes $(n=27)$, neck lymph nodes and lungs $(n=4)$, thyroid bed recurrent lesions $(n=3)$, thyroid bed recurrent lesions and neck lymph nodes $(n=2)$, neck and mediastinal lymph nodes and lungs $(n=1)$, mediastinal lymph nodes and lungs $(n=1)$, and lungs $(n=1)$. Of these 39 patients, $24(62 \%)$ had only lesions with a score of 3 , and the remaining 15 patients $(38 \%)$ had at least 1 lesion with a score of 4 . PET/CT findings led to treatment change in 30 patients $(10 \%)$ from further ${ }^{131}$ I treatment to surgical resection, EBRT, or multikinase inhibitor therapy.

In 15 patients (5\%), both ${ }^{18}$ F-FDG PET/ CT and posttherapy ${ }^{131} \mathrm{I}$ scans showed positive lesions. The same lesions were found on both PET/CT and ${ }^{131}$ I scans in 11 patients (Fig. 2), and the remaining 4 patients had additional lesions on PET/CT. Additionally, of the entire study sample, 8 patients $(3 \%)$ had positive lesions only on the posttherapy ${ }^{131}$ I scan.

\section{${ }^{18}$ F-FDG PET/CT Findings According to Stage}

The ratios of patients with additional lesions on PET/CT and treatment change due to PET/CT findings appeared to follow an upward trend along with a histopathologic stage of the patients $\left(P<0.0001, \chi^{2}\right.$ test for trend). ${ }^{18} \mathrm{~F}$-FDG PET/CT findings according to the histopathologic stage are presented in Table 2 . In the 28 patients undergoing adjuvant ${ }^{131} \mathrm{I}$ treatment after surgical resection of recurrence, the frequency of additional lesions on PET/ CT $(46 \% ; P=0.0001$ for stage T3-T4N1 group, $P<0.0001$ for stage T3-T4N0 and T1-T2N1 groups) and the frequency of treatment change due to PET/CT findings (43\%; $P<0.0001$ for all) were significantly higher than in the other patient groups. Furthermore, in 159 patients with stage T3-T4N1, the frequency of additional lesions on PET/CT (13\%) and the frequency of treatment change due to PET/CT findings $(9 \%)$ were higher than in patients with stage T3-T4N0 or T1-T2N1. However, treatment change occurred in less than $5 \%$ of patients with T3-T4N0 or T1-T2N1.

\section{F-FDG PET/CT Findings According to Age and Tumor Size}

Because age and tumor size are prognostic factors in DTC (1517), we analyzed ${ }^{18}$ F-FDG PET/CT findings accordingly. All 286 
patients were classified into 2 groups according to patients' age at the time of diagnosis of DTC: 90 were 45 y or younger and 196 were older than $45 \mathrm{y}$ at diagnosis. Of those who were $45 \mathrm{y}$ or younger, 14 patients $(16 \%)$ had additional positive lesions on ${ }^{18} \mathrm{~F}$ FDG PET/CT, compared with 25 (13\%) of those who were older than $45 \mathrm{y}$. There was no significant difference between the 2 groups $(P=0.6)$.

Furthermore, 258 patients who underwent ${ }^{131} \mathrm{I}$ ablation after total thyroidectomy were divided into 2 groups according to the tumor size: 190 patients had tumor size $\leq 2.0 \mathrm{~cm}$ and 68 patients had tumor size $>2.0 \mathrm{~cm}$. The 28 patients who underwent adjuvant ${ }^{131}$ I treatment after resection of recurrent tumors were excluded from this analysis. Thirteen patients from each subgroup had additional positive PET/CT lesions (7\% for patients with tumor size $\leq 2.0 \mathrm{~cm}$ and $19 \%$ for patients with tumor size $>2.0 \mathrm{~cm}$ ), and there was a statistically significant difference between the 2 groups $(P=0.008)$.

Because we found that the tumor size was a risk factor for positive findings on PET/CT, we performed further subgroup analysis of the 159 patients with stage T3-T4N1. The patients with stage T3-T4N1 were divided into 2 groups according to the tumor size of $2 \mathrm{~cm}$ : 106 with tumor size $\leq 2.0 \mathrm{~cm}$ and 53 with tumor size $>2.0 \mathrm{~cm}$. In patients with tumor size $>2.0 \mathrm{~cm}$, $13(25 \%)$ had additional positive lesions, compared with 8 patients $(8 \%)$ with tumor size $\leq 2.0 \mathrm{~cm}$. Furthermore, treatment was changed due to PET/CT findings in $17 \%$ (9/53) of patients with tumor size $>2.0 \mathrm{~cm}$, whereas only $6 \%(6 / 106)$ of patients with tumor size $\leq 2.0 \mathrm{~cm}$ had treatment change. Stage T3-T4N1 patients with tumor size $>2.0 \mathrm{~cm}$ had a significantly higher frequency of positive PET/CT findings than stage T3-T4N1 patients with tumor size $\leq 2.0 \mathrm{~cm}(P=0.006)$, stage T3-T4N0 patients $(P=0.007)$, or stage T1-T2N1 patients $(P=0.006)$. Hence, both tumor stage and size can be predictive factors for positive findings on ${ }^{18} \mathrm{~F}-\mathrm{FDG}$ PET/CT (Fig. 3).

\section{${ }^{18}$ F-FDG PET/CT Findings and Serum Thyroglobulin Level}

Of the total 286 patients, $72(25 \%)$ had positive findings for antithyroglobulin antibody. Serum thyroglobulin level was evaluated in the remaining 214 patients (75\%) with negative antithyroglobulin antibody, including 34 of the 50 patients with positive PET/CT lesions and 180 of the 236 patients with negative PET/CT lesions. The mean serum thyroglobulin levels in patients with positive and negative PET/CT lesions were $121.0 \pm 203.1$ $\mathrm{ng} / \mathrm{mL}$ (range, $0.4-1000.0 \mathrm{ng} / \mathrm{mL}$ ) and $7.8 \pm 19.0 \mathrm{ng} / \mathrm{mL}$ (range, $0.1-167.7 \mathrm{ng} / \mathrm{mL}$ ), respectively. There was a statistically significant difference in the serum thyroglobulin levels between the 2 groups $(P<0.0001)$.

Of the 39 patients with additional positive lesions on PET/CT, 13 had positive antithyroglobulin antibody findings. Serum thyroglobulin levels were evaluated in the remaining 26 patients. Furthermore, of the 19 patients with positive lesions on both PET/CT and ${ }^{131} \mathrm{I}$ scans $(n=11)$ or positive lesions on ${ }^{131}$ I scan only $(n=8)$, 4 patients had positive findings for antithyroglobulin antibody, and serum thyroglobulin levels were measured in the remaining 15 patients. Although the serum thyroglobulin level in patients with additional positive lesions on PET/CT (mean value, $138.1 \pm 224.6$ $\mathrm{ng} / \mathrm{mL}$; range, $2.3-1000.0 \mathrm{ng} / \mathrm{mL}$ ) tended to be higher than that in patients with positive lesions on both PET/CT and ${ }^{131} \mathrm{I}$ scan or positive lesions on ${ }^{131} \mathrm{I}$ scan only (mean value, $48.3 \pm 57.0 \mathrm{ng} / \mathrm{mL}$; range, $0.4-184.8 \mathrm{ng} / \mathrm{mL}$ ), there was no statistically significant difference in the serum thyroglobulin levels $(P=0.1$; Fig. 4).

\section{DISCUSSION}

This study demonstrated that ${ }^{18} \mathrm{~F}-\mathrm{FDG}$ PET/CT performed concurrently with ${ }^{131} \mathrm{I}$ treatment can detect additional recurrent or metastatic lesions, which were negative on posttherapy ${ }^{131} \mathrm{I}$ scan, in $14 \%$ of patients with DTC and influence the treatment plan for these patients. Among patients who underwent adjuvant

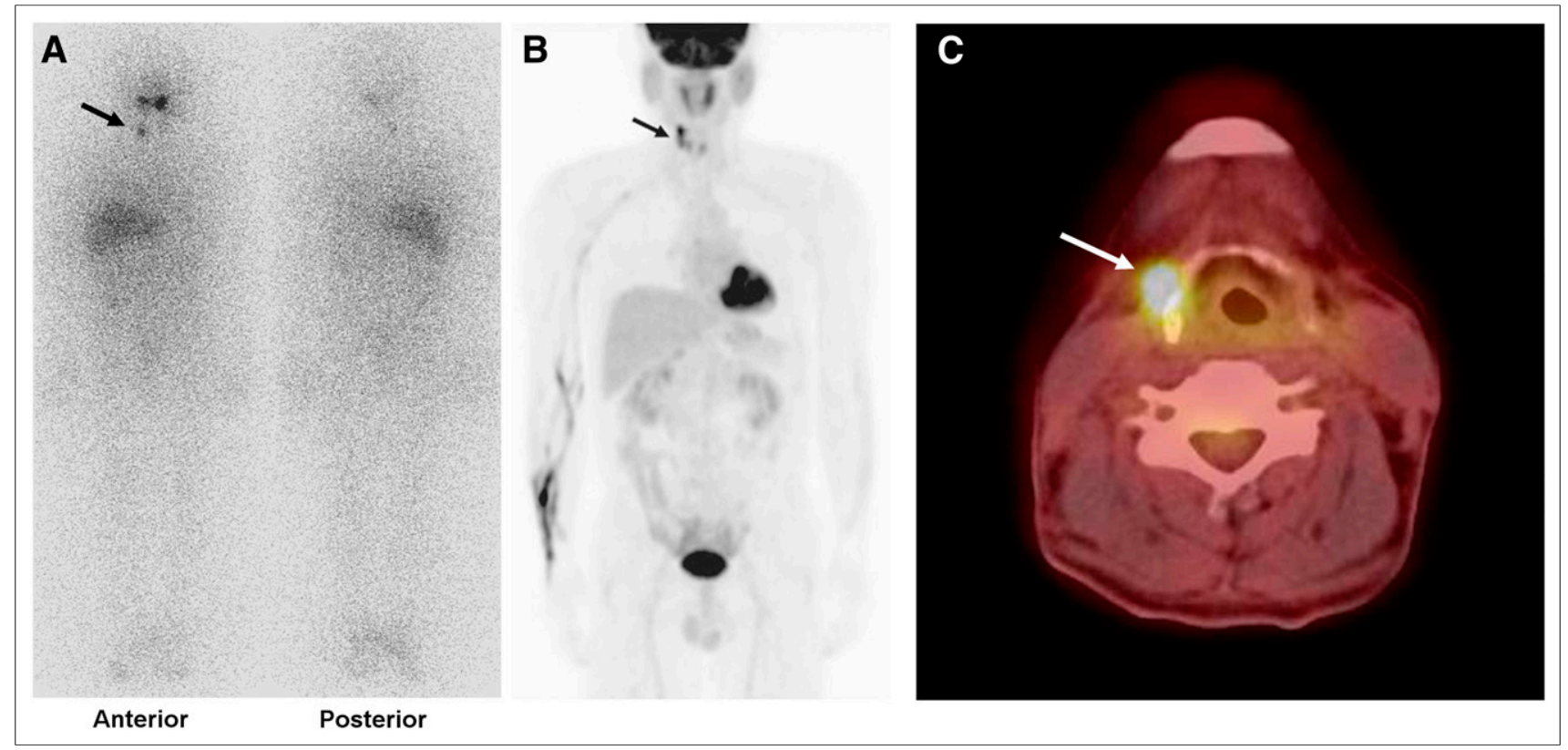

FIGURE 2. A 61 -y-old man with papillary thyroid cancer underwent adjuvant ${ }^{131}$ I treatment (5.6 GBq) 3 mo after neck lymph node dissection for recurrent cancer. Posttherapy ${ }^{131}$ I scan $(A)$ showed focus of increased ${ }^{131}$ I uptake in right neck area (arrow), which also showed increased focal uptake (arrow) on maximal-intensity-projection (B) and transaxial ${ }^{18} \mathrm{~F}-\mathrm{FDG}$ PET/CT (C) images. Lesion was histopathologically confirmed as metastatic lesion. 
TABLE 2

Positive ${ }^{18}$ F-FDG PET/CT Finding and Subsequent Treatment Change According to Stage

\begin{tabular}{lcccr}
\hline \multicolumn{1}{c}{ Stage } & Total patients & Positive PET/CT lesions & Additional positive PET/CT lesions & Treatment change \\
\hline Recurrence & 28 & $16(57)$ & $13(46)$ & $12(43)$ \\
T3-T4N1 & 159 & $28(18)$ & $21(13)$ & $15(9)$ \\
T3-T4N0 & 64 & $4(6)$ & $4(6)$ & $2(3)$ \\
T1-T2N1 & 35 & $2(6)$ & $1(3)$ & $1(3)$ \\
$P$ & & $<0.0001^{\dagger}$ & $<0.0001^{\dagger}$ & $<0.0001^{\dagger}$ \\
\hline
\end{tabular}

*Patients who underwent surgical resection of recurrent tumor lesions after total thyroidectomy.

${ }^{\dagger} \chi^{2}$ test for trend.

Data in parentheses are percentages.

${ }^{131}$ I treatment after operation for recurrence, $46 \%$ had additional positive PET/CT findings. Furthermore, of stage T3-T4N1 patients with tumor size $>2 \mathrm{~cm}$ who underwent ${ }^{131} \mathrm{I}$ ablation, $25 \%$ had additional positive PET/CT findings, suggesting that routine PET/CT performed concurrently with ${ }^{131}$ I therapy should be considered for patients in this group. Tumor stage and size were predictive factors for positive PET/CT findings; however, age and serum thyroglobulin level were not risk factors for positive PET/CT findings.

To date, 2 studies have reported the usefulness of ${ }^{18} \mathrm{~F}-\mathrm{FDG}$ $\mathrm{PET} / \mathrm{CT}$ as an initial staging modality performed with ${ }^{131} \mathrm{I}$ treatment $(14,18)$. Rosenbaum-Krumme et al. (18) performed ${ }^{18} \mathrm{~F}-\mathrm{FDG}$ PET/CT about $1 \mathrm{wk}$ after the first ${ }^{131} \mathrm{I}$ treatment in 90 patients with high-risk DTC. They found that $29 \%$ of patients had positive PET/CT findings, and the treatment strategy for $21 \%$ changed. They also showed that age and serum thyroglobulin level were not predictive factors for the presence of positive PET/CT lesions-a result that agrees with our findings. Iwano et al. (14) performed ${ }^{18}$ F-FDG PET/CT with serum TSH stimulation 3-4 d before ${ }^{131} \mathrm{I}$ ablation in 54 patients with DTC. ${ }^{18}$ F-FDG PET/CT findings were positive in $33 \%$ of enrolled patients, and most of the positive lesions were located in the thyroid bed and cervical lymph nodes. Our study showed that PET/CT found additional lesions in $14 \%$ of patients, and treatment was changed in $10 \%$ of patients, slightly lower proportions than those previously reported $(14,18)$. This difference could be due to the large numbers of patients with intermediate risk in our study. Moreover, the previous studies enrolled a small number of patients with high risk or advanced stage.

We found a high frequency of additional positive PET/CT lesions in patients with recurrent DTC $(46 \%)$ and in patients with stage T3-T4N1 and tumor size $>2 \mathrm{~cm}(25 \%)$. However, only $3 \%-6 \%$ of patients with stage T3-T4N0 or T1-T2N1 had additional PET/ CT findings. Recurrence is found in $16 \%-35 \%$ of DTC patients after initial surgery $(19,20)$, and recurrent DTC cells often exhibit negative ${ }^{131} \mathrm{I}$ uptake and positive findings on ${ }^{18} \mathrm{~F}$-FDG PET/CT due to cell dedifferentiation $(6,21)$. Furthermore, $\mathrm{T}$ stage, presence of nodal metastasis, and tumor size are prognostic factors for DTC that reflect the aggressiveness of cancer cells $(16,17,22,23)$. A previous study has already shown that glucose transporter 1 expression increased with escalating dedifferentiation and aggressiveness of thyroid cancer cells (24). These findings support the idea that a routine ${ }^{18} \mathrm{~F}-\mathrm{FDG}$ PET/CT scan can be beneficial for DTC patients with aggressive clinical features or recurrent lesions. We stratified our patients by tumor stage and size to predict risk of positive PET/CT lesions with negative ${ }^{131}$ I uptake. At our medical centers, ${ }^{18} \mathrm{~F}-\mathrm{FDG}$ PET/CT has routinely been performed at the same time as ${ }^{131} \mathrm{I}$ treatment in patients who underwent curative operation for recurrence or in patients with stage T3-T4N1 and tumor size $>2 \mathrm{~cm}$.

Until recently, the relationship between cell differentiation in DTC and ${ }^{131} \mathrm{I}$ and ${ }^{18} \mathrm{~F}-\mathrm{FDG}$ uptake has been explained according to the so-called flip-flop phenomenon; DTC cells with remaining functional differentiation for iodine uptake are known to exhibit low ${ }^{18}$ F-FDG uptake, whereas dedifferentiated thyroid carcinoma cells with aggressive features show high ${ }^{18}$ F-FDG uptake with a loss of avidity for iodine uptake $(6,25)$. However, we observed simultaneous uptake on both ${ }^{18} \mathrm{~F}-\mathrm{FDG}$ PET/CT and ${ }^{131} \mathrm{I}$ scans in some of our patients (Fig. 2). Previous studies have also found simultaneous uptake of ${ }^{18} \mathrm{~F}-\mathrm{FDG}$ and ${ }^{131} \mathrm{I}$ in metastatic DTC lesions $(18,26)$. On the basis of the results of these studies, Bertagna et al. (27) suggested that iodine and ${ }^{18}$ F-FDG metabolism in DTC could be, at least partly, unrelated. Nevertheless, most patients with metastatic lesions in our study exhibited positive uptake on only the ${ }^{18} \mathrm{~F}$-FDG PET/CT or the ${ }^{131} \mathrm{I}$ scan.

In our study, ${ }^{18}$ F-FDG PET/CT was performed just before ${ }^{131} \mathrm{I}$ treatment on the same day to maximize TSH stimulation and minimize inconvenience to patients. A recent metaanalysis showed that PET scans under TSH stimulation significantly improved the detection of DTC metastases and suggested that TSH stimulation should be recommended for DTC patients undergoing PET scanning (28). Because ${ }^{131} \mathrm{I}$ treatment is performed in patients with an appropriately increased serum thyroglobulin level, with concurrent use of ${ }^{18} \mathrm{~F}$-FDG PET/CT with ${ }^{131} \mathrm{I}$ treatment, TSH-stimulated PET/CT images can be acquired without additional preparation. However, even in TSH-stimulated PET/CT images, $62 \%$ of patients with additional lesions had lesions with a score of 3 . Hence, because many metastatic DTC lesions can still have mildto-moderate ${ }^{18} \mathrm{~F}$-FDG uptake on TSH-stimulated PET images, a careful analysis of PET/CT images is needed.

Although the serum thyroglobulin levels in patients with additional PET/CT-positive lesions tended to be higher than in patients with positive ${ }^{131}$ I scan lesions, there was no significant difference in our study. The serum thyroglobulin level is only indicative of the presence of DTC lesions and tumor burden irrespective of tumor differentiation (29-32). Furthermore, some patients with positive PET/CT findings in the present study had low serum thyroglobulin levels of $<10.0 \mathrm{ng} / \mathrm{mL}$ with TSH stimulation, suggesting that DTC patients with low serum thyroglobulin levels can also have positive PET/CT findings.

Though pretherapy radioiodine scanning was not performed in our study, the American Thyroid Association recommends pretherapy scanning when the extent of the thyroid remnant cannot be 

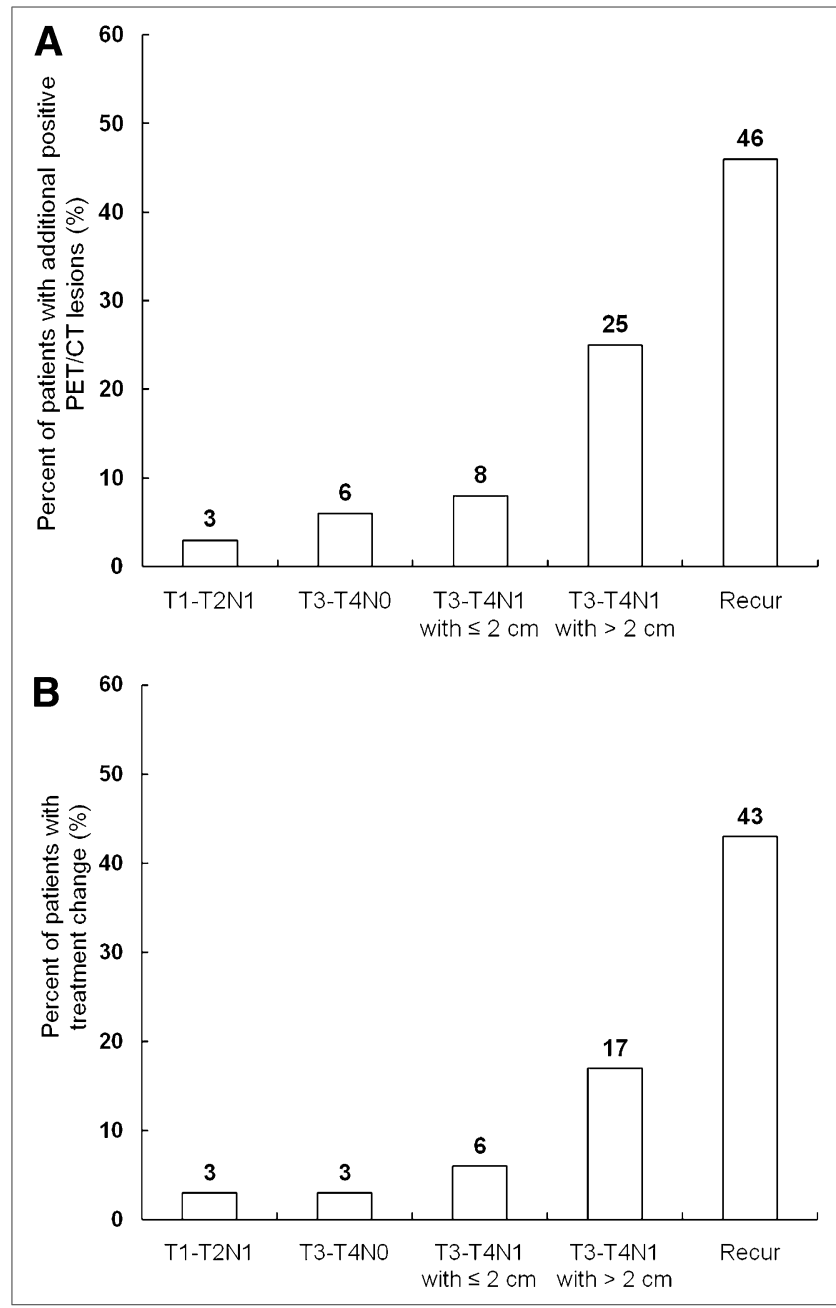

FIGURE 3. Ratios of patients with additional positive lesions on ${ }^{18} \mathrm{~F}-\mathrm{FDG} \mathrm{PET} / \mathrm{CT}(\mathrm{A})$ and ratios of patients with treatment change due to PET/CT findings (B). Stage T3-T4N1 patients with tumor size $>2.0 \mathrm{~cm}$ and patients who underwent adjuvant ${ }^{131}$ I treatment after operation for recurrence had higher frequency of positive PET/CT findings and treatment change than stage T3-T4N1 patients with tumor size $\leq 2.0 \mathrm{~cm}$, stage T3-T4N0 patients, or stage T1-T2N1 patients $(P<0.05)$. T3-T4N1 with $\leq 2 \mathrm{~cm}=$ stage T3-T4N1 patients with tumor size $\leq 2 \mathrm{~cm}$; T3-T4N1 with $>2 \mathrm{~cm}=$ stage T3-T4N1 patients with tumor size $>2 \mathrm{~cm}$; Recur $=$ patients who underwent adjuvant ${ }^{131}$ I treatment after operation for recurrent tumor.

ascertained or when the results would alter the treatment plan or the dose of ${ }^{131} \mathrm{I}$ (1). TSH-stimulated PET/CT imaging can be performed with pretherapy scanning for detecting iodine-negative lesions before ${ }^{131} \mathrm{I}$ treatment. However, there is still a debate whether pretherapy ${ }^{123}$ I scanning can achieve results comparable to posttherapy ${ }^{131}$ I scanning (33-35). Therefore, careful consideration is needed to diagnose iodine-negative lesions based on pretherapy ${ }^{123}$ I scans.

There are several limitations in our study. First, because the present study was retrospectively performed, selection bias could have affected the results. Second, all the patients were Korean. Because dietary patterns and genetic mutation for DTC in Koreans are different from those in other ethnic groups $(36,37)$, further studies are needed to establish concurrent ${ }^{18} \mathrm{~F}-\mathrm{FDG}$ PET/CT and ${ }^{131}$ I therapy as a standard procedure in other countries. Third, only planar posttherapy ${ }^{131} \mathrm{I}$ images were obtained in the study, and

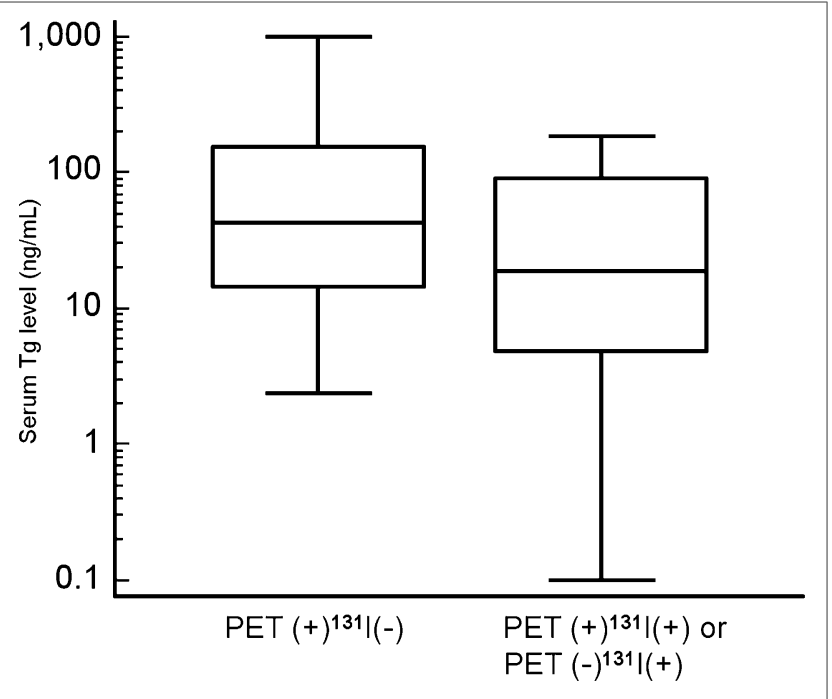

FIGURE 4. Serum thyroglobulin values in patients with additional positive lesions on ${ }^{18} \mathrm{~F}-\mathrm{FDG}$ PET/CT $\left(\mathrm{PET}(+)^{131} \mathrm{I}(-)\right.$ group) and in patients with positive lesions on both PET/CT and ${ }^{131}$ I scan or with positive lesions on only ${ }^{131}$ I scan $\left(\operatorname{PET}(+)^{131} \mid(+)\right.$ or PET $(-)^{131} \mid(+)$ group). There was no significant difference in serum thyroglobulin level between the 2 groups $(P>0.05)$.

SPECT was not performed. Further studies that compare PET/ CT with SPECT/CT will be needed to confirm the clinical utility of PET/CT. Finally, not all positive PET/CT lesions were histopathologically confirmed, especially distant metastatic lesions. However, because these positive PET/CT lesions were verified by follow-up imaging studies, it could not significantly influence the results.

\section{CONCLUSION}

The present study demonstrated that ${ }^{18} \mathrm{~F}-\mathrm{FDG}$ PET/CT performed concurrently with ${ }^{131} \mathrm{I}$ treatment detects additional iodine-negative metastatic foci in $14 \%$ of DTC patients, resulting in a change in further management of many of such patients. Tumor stage and size predict the likelihood of detecting ${ }^{18} \mathrm{~F}-\mathrm{FDG}$-avid lesions. Therefore, we recommend concurrent ${ }^{18} \mathrm{~F}$-FDG PET/CT imaging with ${ }^{131}$ I treatment in DTC patients with recurrent tumors or aggressive clinical features.

\section{DISCLOSURE}

The costs of publication of this article were defrayed in part by the payment of page charges. Therefore, and solely to indicate this fact, this article is hereby marked "advertisement" in accordance with 18 USC section 1734. This work was supported in part by the Soonchunhyang University Research Fund. No other potential conflict of interest relevant to this article was reported.

\section{REFERENCES}

1. Cooper DS, Doherty GM, Haugen BR, et al. Revised American Thyroid Association management guidelines for patients with thyroid nodules and differentiated thyroid cancer. Thyroid. 2009;19:1167-1214.

2. Mazzaferri EL, Jhiang SM. Long-term impact of initial surgical and medical therapy on papillary and follicular thyroid cancer. Am J Med. 1994;97:418-428.

3. Sawka AM, Thephamongkhol K, Brouwers M, Thabane L, Browman G, Gerstein HC. Clinical review 170: a systematic review and metaanalysis of the 
effectiveness of radioactive iodine remnant ablation for well-differentiated thyroid cancer. J Clin Endocrinol Metab. 2004;89:3668-3676.

4. Rouxel A, Hejblum G, Bernier MO, et al. Prognostic factors associated with the survival of patients developing loco-regional recurrences of differentiated thyroid carcinomas. J Clin Endocrinol Metab. 2004;89:5362-5368.

5. Mirallié E, Guillan T, Bridji B, et al. Therapeutic impact of ${ }^{18}$ FDG-PET/CT in the management of iodine-negative recurrence of differentiated thyroid carcinoma. Surgery. 2007;142:952-958.

6. Makeieff M, Burcia V, Raingeard I, et al. Positron emission tomography-computed tomography evaluation for recurrent differentiated thyroid carcinoma. Eur Ann Otorhinolaryngol Head Neck Dis. 2012;129:251-256.

7. Miller ME, Chen Q, Elashoff D, Abemayor E, St John M. Positron emission tomography and positron emission tomography-CT evaluation for recurrent papillary thyroid carcinoma: meta-analysis and literature review. Head Neck. 2011; 33:562-565.

8. Palmedo H, Bucerius J, Joe A, et al. Integrated PET/CT in differentiated thyroid cancer: diagnostic accuracy and impact on patient management. J Nucl Med. 2006;47:616-624.

9. Giammarile F, Hafdi Z, Bournaud C, et al. Is $\left[{ }^{18} \mathrm{~F}\right]$-2-fluoro-2-deoxy-D-glucose (FDG) scintigraphy with non-dedicated positron emission tomography useful in the diagnostic management of suspected metastatic thyroid carcinoma in patients with no detectable radioiodine uptake? Eur J Endocrinol. 2003;149:293-300.

10. Leboulleux S, El Bez I, Borget I, et al. Post-radioiodine treatment whole body scan in the era of fluorodesoxyglucose positron emission tomography for differentiated thyroid carcinoma with elevated serum thyroglobulin levels. Thyroid. 2012;22:832-838.

11. Saab G, Driedger AA, Pavlosky W, et al. Thyroid-stimulating hormone-stimulated fused positron emission tomography/computed tomography in the evaluation of recurrence in ${ }^{131}$ I-negative papillary thyroid carcinoma. Thyroid. 2006;16:267-272.

12. Petrich T, Borner AR, Otto D, Hofmann M, Knapp WH. Influence of rhTSH on $\left[{ }^{18} \mathrm{~F}\right]$ fluorodeoxyglucose uptake by differentiated thyroid carcinoma. Eur J Nucl Med Mol Imaging. 2002;29:641-647.

13. Leboulleux S, Schroeder PR, Busaidy NL, et al. Assessment of the incremental value of recombinant thyrotropin stimulation before 2-[ $\left.{ }^{18} \mathrm{~F}\right]$-fluoro-2-deoxy-Dglucose positron emission tomography/computed tomography imaging to localize residual differentiated thyroid cancer. J Clin Endocrinol Metab. 2009;94: 1310-1316.

14. Iwano S, Kato K, Ito S, Tsuchiya K, Naganawa S. FDG-PET performed concurrently with initial I-131 ablation for differentiated thyroid cancer. Ann Nucl Med. 2012;26:207-213.

15. Wang W, Larson SM, Fazzari M, et al. Prognostic value of $\left[{ }^{18} \mathrm{~F}\right]$ fluorodeoxyglucose positron emission tomographic scanning in patients with thyroid cancer. J Clin Endocrinol Metab. 2000;85:1107-1113.

16. Krämer JA, Schmid KW, Dralle H, et al. Primary tumour size is a prognostic parameter in patients suffering from differentiated thyroid carcinoma with extrathyroidal growth: results of the MSDS trial. Eur J Endocrinol. 2010;163:637-644.

17. Ito Y, Kudo T, Kihara M, et al. Prognosis of low-risk papillary thyroid carcinoma patients: its relationship with the size of primary tumors. Endocr J. 2012;59:119-125.

18. Rosenbaum-Krumme SJ, Gorges R, Bockisch A, Binse I. ${ }^{18}$ F-FDG PET/CT changes therapy management in high-risk DTC after first radioiodine therapy. Eur J Nucl Med Mol Imaging. 2012;39:1373-1380.

19. Hay ID, Bergstralh EJ, Grant CS, et al. Impact of primary surgery on outcome in 300 patients with pathologic tumor-node-metastasis stage III papillary thyroid carcinoma treated at one institution from 1940 through 1989. Surgery. 1999; 126:1173-1181.
20. Mazzaferri EL, Kloos RT. Clinical review 128: Current approaches to primary therapy for papillary and follicular thyroid cancer. $J$ Clin Endocrinol Metab. 2001;86:1447-1463.

21. Razfar A, Branstetter BF 4th, Christopoulos A, et al. Clinical usefulness of positron emission tomography-computed tomography in recurrent thyroid carcinoma. Arch Otolaryngol Head Neck Surg. 2010;136:120-125.

22. Konturek A, Barczynski M, Nowak W, Richter P. Prognostic factors in differentiated thyroid cancer: a 20-year surgical outcome study. Langenbecks Arch Surg. 2012;397:809-815.

23. Huang BY, Lin JD, Chao TC, Lin KJ, Hseuh C, Tsang NM. Therapeutic outcomes of papillary thyroid cancer patients in different risk groups. Oncology. 2011;80:123-129.

24. Grabellus F, Nagarajah J, Bockisch A, Schmid KW, Sheu SY. Glucose transporter 1 expression, tumor proliferation, and iodine/glucose uptake in thyroid cancer with emphasis on poorly differentiated thyroid carcinoma. Clin Nucl Med. 2012;37:121-127.

25. Feine U, Lietzenmayer R, Hanke JP, Held J, Wohrle H, Muller-Schauenburg W. Fluorine-18-FDG and iodine-131-iodide uptake in thyroid cancer. $J$ Nucl Med. 1996;37:1468-1472.

26. Piccardo A, Foppiani L, Morbelli S, et al. Could [18]F-fluorodeoxyglucose PET/ CT change the therapeutic management of stage IV thyroid cancer with positive ${ }^{131}$ I whole body scan? Q J Nucl Med Mol Imaging. 2011;55:57-65.

27. Bertagna F, Giubbini R. Comment on Rosenbaum-Krumme et al. ${ }^{18}$ F-FDG PET/ CT changes therapy management in high-risk DTC after first radioiodine therapy. Eur J Nucl Med Mol Imaging. 2012;39:1658-1659.

28. Ma C, Xie J, Lou Y, Gao Y, Zuo S, Wang X. The role of TSH for ${ }^{18}$ F-FDG-PET in the diagnosis of recurrence and metastases of differentiated thyroid carcinoma with elevated thyroglobulin and negative scan: a meta-analysis. Eur J Endocrinol. 2010;163:177-183.

29. Bachelot A, Cailleux AF, Klain M, et al. Relationship between tumor burden and serum thyroglobulin level in patients with papillary and follicular thyroid carcinoma. Thyroid. 2002;12:707-711.

30. Pellegriti G, Scollo C, Regalbuto C, et al. The diagnostic use of the rhTSH/ thyroglobulin test in differentiated thyroid cancer patients with persistent disease and low thyroglobulin levels. Clin Endocrinol (Oxf). 2003;58:556-561.

31. Robbins RJ, Srivastava S, Shaha A, et al. Factors influencing the basal and recombinant human thyrotropin-stimulated serum thyroglobulin in patients with metastatic thyroid carcinoma. J Clin Endocrinol Metab. 2004;89:6010-6016.

32. Spencer CA, LoPresti JS, Fatemi S, Nicoloff JT. Detection of residual and recurrent differentiated thyroid carcinoma by serum thyroglobulin measurement. Thyroid. 1999;9:435-441.

33. Thomas DL, Menda Y, Bushnell D. A comparison between diagnostic I-123 and posttherapy I-131 scans in the detection of remnant and locoregional thyroid disease. Clin Nucl Med. 2009;34:745-748.

34. Iwano S, Kato K, Nihashi T, Ito S, Tachi Y, Naganawa S. Comparisons of I-123 diagnostic and I-131 post-treatment scans for detecting residual thyroid tissue and metastases of differentiated thyroid cancer. Ann Nucl Med. 2009;23:777-782.

35. Chen MK, Yasrebi M, Samii J, Staib LH, Doddamane I, Cheng DW. The utility of I-123 pretherapy scan in I-131 radioiodine therapy for thyroid cancer. Thyroid. 2012;22:304-309.

36. Kim KH, Kang DW, Kim SH, Seong IO, Kang DY. Mutations of the BRAF gene in papillary thyroid carcinoma in a Korean population. Yonsei Med J. 2004;45: 818-821.

37. Kim JY, Moon SJ, Kim KR, Sohn CY, Oh JJ. Dietary iodine intake and urinary iodine excretion in normal Korean adults. Yonsei Med J. 1998;39:355-362. 